\title{
Analisis Faktor-Faktor yang Menentukan Kepuasan Kerja dan Loyalitas Karyawan (Studi Kasus di Perusahaan Kopi PT Golden Kirrin Internasional, Kabupaten Badung)
}

\author{
DESMAN ARIANTO SITINJAK, I GUSTI AYU OKA SURYAWARDANI, \\ PUTU UDAYANI WIJAYANTI
}

\author{
J1. PB. Sudirman Denpasar 80233 \\ Email: sitinjakdesman@gmail.com \\ gungdani@gmail.com
}

Program Studi Agribisnis, Fakultas Pertanian, Universitas Udayana

\begin{abstract}
The Analysis the Factors that Determinate Employee's Job Satisfaction and Loyalty (The Case at Company's Coffee by Golden Kirrin International, Badung Regency)
\end{abstract}

This research aims to analyze the factors that determine the job satisfaction and employee loyalty in PT Golden Kirrin International. The research was conducted in the agro-tourism company PT Golden Kirrin International, Badung Regency, Bali Province, with 109 respondents interviewed. The data were analyzed by exploratory factor analysis using SPSS. The results showed that job satisfaction and loyalty of employees of PT Golden Kirrin International supported by three factors, namely: social factor with the indicators are: motivation, the attitude of the leadership relationship led to the employee, employee relations with employees, work space, and punishment. Salary/wage factor with the indicators are: salaries/wages, allowance (Tunjangan Hari Raya), bonuses, job description, holidays, and reward. Work assurance factor with the indicators are: job security and safety assurance. The result of the assessment employee loyalty was analyzed from three indicators showed an excellent result, employees are very satisfied with company's and employee's performance and employees are very loyal to the company PT Golden Kirrin Internasional. The advice that can be given on the result of this study to PT Golden Kirrin International is that the leadership of PT Golden Kirrin International must maintain the level of satisfaction and loyalty of its employees, especially in the social and salary/wage factors. Because these factors are very significant impact on the achievements that have been set by the company. As for, the work assurance factor corporate leaders still have to pay attention, because this factor supports the creation of the welfare of the employees working.

Keywords: company, job satisfaction, loyalty, employee 


\section{Pendahuluan}

\subsection{Latar Belakang}

Karyawan merupakan aset perusahaan yang sangat berharga yang harus dikelola dengan baik oleh perusahaan agar dapat memberikan kontribusi yang optimal. Salah satu yang harus menjadi perhatian utama perusahaan adalah kepuasan kerja. Kepuasan kerja pada dasarnya memiliki tingkat kepuasan kerja yang berbeda-beda sesuai dengan keinginan dan sistem nilai yang dianut nya (Handoko, 2000). Kepuasan kerja tidak hanya sekedar melakukan pekerjaan, tetapi terkait juga dengan aspek lain Hariandja (2002).

Ketidakpuasan kerja muncul saat harapan-harapan itu tidak terpenuhi (Mathis dan Jackson, 2001). Menurut Maslow dalam Teori Hierarki Kebutuhan (Hierarchical of Needs Theory), dijelaskan ada lima kebutuhan pada setiap manusia. Adapun kelimanya adalah kebutuhan secara fisiologis, rasa aman, sosial, penghargaan, dan aktualisasi diri. Berdasarkan lima kebutuhan tersebut, maka tingkat kepuasan kerja karyawan tidak hanya diukur dari kompensasi atau gaji yang diberikan perusahaan kepada karyawannya, namun juga tingkat kepuasan kerja karyawan juga dapat dinilai dari kesesuaian pekerjaan yang ditekuninya, pengembangan karier, lingkungan kerja, dan perilaku atasan terhadap bawahan. Jika keseluruhan sudah berjalan baik di perusahaan, diyakini dapat memotivasi semangat kerja karyawan agar karyawan dapat memberikan hasil yang terbaik bagi perusahaan sehingga kinerja perusahaan dapat ditingkatkan. Simamora mengungkapkan dalam buku Manajemen Sumber Daya Manusia (1995) kinerja karyawan adalah suatu kondisi bahwa para karyawan mencapai persyaratan-persyaratan pekerjaan yang ditetapkan oleh perusahaan.

PT Golden Kirrin Internasional merupakan perusahaan yang bergerak di bidang agroindustri hasil pertanian dengan produk kopi. Perusahaan ini berlokasi Jl. Parigata No.708, Jimbaran. Perusahaan ini memiliki tenaga kerja 150 orang. Tenaga kerja yang paling lama bekerja di perusahaan terdapat pada masa bekerja tiga belas tahun dan terkecil adalah kurang dari satu tahun. Berdasarkan yang diamati di lapangan ternyata masih ada ditemukan pengelolaan sumber daya manusia yang belum maksimal di perusahaan ini seperti: seleksi jenjang karier seorang karyawan diperusahaan ini cukup minimim. Waktu libur karyawan di perusahaan ini tidak memiliki waktu libur weekend. Hal-hal diatas memang memberikan benefit bagi perusahaan, namun juga mampu berpotensi menurunkan kepuasan kerja hingga potensi penarikan diri seorang karyawan, namun faktanya masih ada ditemukan karyawan memilih tetap bertahan bekerja diperusahaan ini meski dengan kondisi demikian. Kondisi ini merupakan suatu fenomena yang tidak biasa terjadi atau unik dan patut untuk dipelajari lebih lanjut. Melihat kondisi seperti ini, maka penelitian terhadap faktor-faktor yang menentukan kepuasan kerja dan loyalitas karyawan di perusahaan kopi PT Golden Kirrin Internasional perlu dilakukan, jika kondisi kondisi tersebut tidak disikapi dan dikelola dengan baik oleh perusahaan dapat berpotensi merugikan perusahaan sendiri, sebab karyawan merupakan ujung tombak bagi perusahaan tanpa ada karyawan segala kegiatan operasional di perusahaan tidak bisa berjalan. 


\subsection{Rumusan Masalah}

Berdasarkan latar belakang diatas, maka dapat dirumuskan permasalahan yaitu:

1. Indikator-indikator apa saja yang membentuk faktor kepuasan kerja dan loyalitas karyawan di PT Golden Kirrin Internasional.

2. Bagaimanakah loyalitas karyawan PT Golden Kirrin Internasional.

\subsection{Tujuan Penelitian}

Adapun tujuan penelitian ini adalah:

1. Mengidentifikasi indikator-indikator dalam membentuk faktor kepuasan kerja dan loyalitas di PT Golden Kirrin Internasional.

2. Menganalisis kepuasan kerja dan loyalitas karyawan di PT Golden Kirrin Internasional.

\section{Metode Penelitian}

\subsection{Metode dan Waktu Penelitian}

Penelitian ini dilaksanakan di perusahaan agrowisata PT Golden Kirrin Internasional, Jimbaran, Kabupaten Badung, Provinsi Bali. Pemilihan lokasi ini dipilih dengan metode purposive. Penelitian akan dilaksanakan pada bulan Januari hingga bulan Maret 2017.

\subsection{Jenis dan Sumber Data}

Jenis data yang digunakan dalam penelitian ini di bagi menjadi tiga, yaitu: data kuantitatif, data kualitatif, dan data kualitatif yang dikuantitatifkan. Berdasarkan sumbernya, data yang digunakan pada penelitian ini terdiri dari: data primer yang diperoleh melalui proses wawancara dengan seluruh karyawan menggunakan kuesioner. Data sekunder diperoleh dari dokumen, buku-buku yang relevan dengan penelitian, dan internet. Metode pengumpulan data penelitian ini dilakukan dengan cara wawancara dan observasi.

\subsection{Metode Sampel}

Populasi dalam penelitian ini adalah 150 orang karyawan PT Golden Kirrin Internasional. Penentukan responden yang menggambarkan populasi, digunakan rumus Slovin dengan nilai batas toleransi kesalahan (error tolerance) sebesar 5\% (Sevilla et al, 2007), sehingga jumlah responden yang diteliti sebanyak 109 karyawan. Teknik pengambilan sampel menggunakan metode simple random sampling supaya anggota populasi memiliki kesempatan yang sama (Istijanto, 2005: 114).

\subsection{Variabel dan Indikator}

Variabel dapat diartikan sebagai sesuatu yang akan menjadi objek pengamatan penelitian yang mempunyai nilai bervariasi (Antara, 2006). Variabel pada penelitian ini terbagi atas dua, yaitu variabel bebas (independent) terdiri dari, yaitu: gaji/upah dan kompensasi, kepemimpinan, aspek sosial dalam pekerjaan, lingkungan kerja, 
penghargaan, sanksi kerja, dan jaminan bekerja. Variabel terikat (dependent) yaitu kepuasan kerja dan loyalitas karyawan PT Golden Kirrin Internasional.

\subsection{Metode Analisis Data}

Penelitian ini menggunakan metode analisis faktor eksploratori yang dibantu program SPSS versi 20. Tingkat kepuasan dan loyalitas karyawan diukur berdasarkan Skala Likert dengan skor yang telah ditentukan, yaitu: sangat puas dengan skor 5, puas dengan skor 4, cukup puas dengan skor 3, tidak puas dengan skor 2, sangat tidak puas dengan skor 1. Pengukuran loyalitas karyawan sendiri digunakan rumus interval kelas. Pemilihan ini dilakukan untuk memudahkan melihat hasil data yang diperoleh yang didistribusikan ke dalam kategori atau kelas yang diinginkan.

\subsection{Uji Instrument Penelitian}

Data pada penelitian ini dilakukan pengujian validitas untuk mengukur apa yang seharusnya di ukur (Sugiyono, 2008). Reabilitas untuk menujukkan adanya konsistensi dan stabilitas nilai hasil skala pengukuran (Sarwono dan Martadiredja, 2008). Normalitas data untuk menguji apakah dalam variabel-variabel memiliki distribusi normal atau tidak. Ketiga uji instrument berfungsi mengetahui apakah data pada penelitian layak untuk dianalisis pada analisis selanjutnya.

\section{Hasil dan Pembahasan}

\subsection{Nilai Eigenvalue sebagai Pembentuk Faktor}

Tabel Total Variance Explained, menggambarkan jumlah faktor yang mungkin terbentuk. Melihat jumlah faktor yang terbentuk harus terlebih dahulu memperhatikan nilai eigenvalue. Faktor dikatakan terbentuk apabila nilai eigenvalue $>1$. Jumlah nilai eigenvalue, selalu diurutkan dari nilai yang terbesar hingga yang terkecil (Santoso, 2015: 83).

Berdasarkan penelitian dapat dilihat bahwa dari 14 indikator yang di analisis hanya terbentuk tiga component (faktor). Varians yang mampu diterangkan oleh component (faktor) 1 adalah 7,485/14 x 100\% =53,462\%, sementara oleh component (faktor) 2 sebesar 1,245/14 x 100\% =8,891\% dan component (faktor) 3 sebesar $1.100 / 14 \times 100 \%=7,855 \%$. Total ketiga faktor akan mampu menjelaskan indikator sebesar $53,462 \%+8,891 \%+7,885 \%$, atau 70,207\% dari 14 indikator, sedangkan $29,793 \%$ lagi tidak dapat dijelaskan pada penelitian ini. Jumlah eigenvalue untuk 14 indikator adalah sama dengan total varians 14 indikator, atau 7,845 +1,245 +1,100+ $0,869+0,683+0,561+0,416+0,359+0,327+0,274+0,217+0,167+0,159+$ $0,139=14$. Kesimpulannya bahwa hanya ada 3 faktor yang terbentuk karena ketiga faktor tersebut memiliki nilai eigenvalue 7,845, 1,245 dan 1,100 (>1). Selengkapnya perhatikan tabel 1 . 
Tabel 1.

Hasil Uji Total Variance Explained

\begin{tabular}{|c|c|c|c|c|c|c|c|c|c|}
\hline \multirow{2}{*}{$\begin{array}{l}\text { Co } \\
m p \\
\text { one } \\
n t\end{array}$} & \multicolumn{3}{|c|}{ Initial Eigenvalues } & \multicolumn{3}{|c|}{$\begin{array}{l}\text { Extraction Sums of } \\
\text { Squared Loadings }\end{array}$} & \multicolumn{3}{|c|}{$\begin{array}{c}\text { Rotation Sums of Squared } \\
\text { Loadings }\end{array}$} \\
\hline & Total & $\begin{array}{c}\% \text { of } \\
\text { Varia } \\
\text { nce }\end{array}$ & $\begin{array}{c}\text { Cumul } \\
\text { ative } \\
\%\end{array}$ & Total & $\begin{array}{c}\% \text { of } \\
\text { Varia } \\
\text { nce }\end{array}$ & $\begin{array}{l}\text { Cumul } \\
\text { ative \% }\end{array}$ & $\begin{array}{c}\text { Tota } \\
l\end{array}$ & $\begin{array}{c}\% \text { of } \\
\text { Varian } \\
\text { ce }\end{array}$ & $\begin{array}{c}\text { Cumul } \\
\text { ative } \\
\%\end{array}$ \\
\hline 1 & 7,485 & 53,462 & 53,462 & $\begin{array}{r}7,48 \\
5\end{array}$ & $\begin{array}{r}53,46 \\
2\end{array}$ & 53,462 & $\begin{array}{r}4,07 \\
6\end{array}$ & 29,111 & 29,111 \\
\hline 2 & 1,245 & 8,891 & 62,353 & $\begin{array}{r}1,24 \\
5\end{array}$ & 8,891 & 62,353 & $\begin{array}{r}3,61 \\
6\end{array}$ & 25,826 & 54,938 \\
\hline 3 & 1.100 & 7,855 & 70,207 & $\begin{array}{r}1,10 \\
0\end{array}$ & 7,855 & 70,207 & $\begin{array}{r}2,13 \\
8\end{array}$ & 15,270 & 70,207 \\
\hline 4 & 0,869 & 6,208 & 76,415 & & & & & & \\
\hline 5 & 0,683 & 4,876 & 81,291 & & & & & & \\
\hline 6 & 0,561 & 4,010 & 85,301 & & & & & & \\
\hline 7 & 0,416 & 2,970 & 88,271 & & & & & & \\
\hline 8 & 0,359 & 2,566 & 90,837 & & & & & & \\
\hline 9 & 0,327 & 2,339 & 93,176 & & & & & & \\
\hline 10 & 0,274 & 1,957 & 95,133 & & & & & & \\
\hline 11 & 0,217 & 1,550 & 96,683 & & & & & & \\
\hline 12 & 0,167 & 1,193 & 97,876 & & & & & & \\
\hline 13 & 0,159 & 1,133 & 99,009 & & & & & & \\
\hline 14 & 0,139 & 0,991 & $\begin{array}{r}100,00 \\
0\end{array}$ & & & & & & \\
\hline
\end{tabular}

Extraction Method: Principal Component Analysis.

Sumber: Hasil output SPSS

\subsection{Peranan Indikator dalam Menentukan Faktor}

Kemampuan indikator dalam menjelaskan faktor dapat dilihat dari nilai Communalities. Menurut Santoso (2015: 82), semakin besar nilai Communalities maka semakin tinggi peranan indikator dalam menjelaskan faktor yang terbentuk.

Tabel 2.

Hasil Uji Communalities

\begin{tabular}{|c|c|c|c|c|}
\hline No & Variabel & Indikator & Simbol & Communalities \\
\hline 1 & $\begin{array}{l}\text { Gaji/upah } \\
\text { dan kompensasi }\end{array}$ & $\begin{array}{l}\text { a. Gaji } \\
\text { b. THR } \\
\text { c. Bonus }\end{array}$ & $\begin{array}{l}\text { a. } \mathrm{X} 1.1 \\
\text { b. } \mathrm{X} 1.2 \\
\text { c. } \mathrm{X} 1.3\end{array}$ & $\begin{array}{l}0,769 \\
0,755 \\
0,699\end{array}$ \\
\hline 2 & Kepemimpinan & $\begin{array}{l}\text { a. Motivasi } \\
\text { b. Sikap pimpinan }\end{array}$ & $\begin{array}{ll}\text { a. } & \mathrm{X} 2.1 \\
\text { b. } & \mathrm{X} 2.2\end{array}$ & $\begin{array}{l}0,738 \\
0,719\end{array}$ \\
\hline 3 & $\begin{array}{l}\text { Aspek sosial dalam } \\
\text { pekerjaan }\end{array}$ & $\begin{array}{l}\text { a. Pimpinan \& } \\
\text { Karyawan } \\
\text { b. Karyawan \& } \\
\text { karyawan } \\
\end{array}$ & $\begin{array}{l}\text { a. } \mathrm{X} 3.1 \\
\text { b. } \mathrm{X} 3.2\end{array}$ & $\begin{array}{l}0,580 \\
0,696\end{array}$ \\
\hline 4 & Lingkungan kerja & $\begin{array}{l}\text { a. Job description } \\
\text { b. Libur } \\
\text { c. Ruangan }\end{array}$ & $\begin{array}{l}\text { a. } \mathrm{X} 4.1 \\
\text { b. } \mathrm{X} 4.2 \\
\text { c. } \mathrm{X} 4.3\end{array}$ & $\begin{array}{l}0,645 \\
0,511 \\
0,718\end{array}$ \\
\hline 5 & $\begin{array}{l}\text { Penghargaan dan sanksi } \\
\text { kerja }\end{array}$ & $\begin{array}{l}\text { a. Reward } \\
\text { b. Punishment }\end{array}$ & $\begin{array}{l}\text { a. } \times 5.1 \\
\text { b. } \times 5.2\end{array}$ & $\begin{array}{l}0,717 \\
0,634\end{array}$ \\
\hline 6 & Jaminan berkerja & $\begin{array}{l}\text { a. Keselamatan kerja } \\
\text { b. Jaminan kesehatan }\end{array}$ & $\begin{array}{l}\text { a. X6.1 } \\
\text { b. X6.2 }\end{array}$ & $\begin{array}{l}0,859 \\
0,801\end{array}$ \\
\hline
\end{tabular}

Sumber: Hasil output SPSS 
Distribusi 14 indikator pada ketiga faktor yang terbentuk dapat dilihat pada tabel 2. Angka-angka pada tabel tersebut menunjukkan besarnya varians dari indikator yang mampu dijelaskan oleh faktor yang terbentuk. Contohnya indikator gaji memiliki korelasi sebesar 76,9\% terhadap faktor yang terbentuk, demikian seterusnya.

Proses selanjutnya, penentuan indikator dalam membentuk faktor dapat dilihat dari perbandingan besarnya nilai korelasi pada setiap baris (Santoso, 2015: 84). Lebih jelasnya dapat dilihat pada tabel 3 .

Tabel 3.

Hasil Uji Component Matrix

\begin{tabular}{lcrr}
\hline & \multicolumn{3}{c}{ Component (Variable) } \\
\cline { 2 - 4 } & 1 & 2 & 3 \\
\hline Gaji/Upah & 0,702 & $-0,495$ & 0,176 \\
THR & 0,683 & $-0,548$ & $-0,095$ \\
Bonus & 0,726 & $-0,337$ & $-0,167$ \\
Motivasi & 0,740 & 0,337 & $-0,277$ \\
Sikap pimpinan & 0,756 & 0,262 & $-0,279$ \\
Hubungan Pimpinan-Karyawan & 0,706 & 0,282 & $-0,033$ \\
Hubungan Karyawan-Karyawan & 0,721 & 0,411 & $-0,085$ \\
Job description & 0,776 & $-0,109$ & 0,173 \\
Libur & 0,691 & $-0,159$ & $-0,089$ \\
Ruang kerja & 0,847 & 0,005 & $-0,034$ \\
Reward & 0,827 & $-0,099$ & $-0,149$ \\
Punishment & 0,763 & 0,135 & $-0,183$ \\
Jaminan keselamatan & 0,686 & 0,032 & 0,622 \\
Jaminan kesehatan & 0,570 & 0,298 & 0,622 \\
\hline
\end{tabular}

Extraction Method: Principal Component Analysis.

a. 3 components extracted.

Sumber: Hasil output SPSS

Tabel 3 menunjukkan nilai korelasi masing-masing indikator terhadap faktor yang terbentuk adalah sebagai berikut: gaji/upah: Faktor 1 korelasi 0,702; Faktor 2 korelasi -0,495; Faktor 3 korelasi 0,176. THR; Faktor 1 korelasi 0,683; Faktor 2 korelasi -0,548; Faktor 3 korelasi -0,095 demikian seterusnya hingga jaminan kesehatan: Faktor 1 korelasi 0,570; Faktor 2 korelasi 0,298; Faktor 3 korelasi 0,622.

Proses pembentukan faktor oleh indikator pembentuknya dapat dilihat dari hasil uji Rotated Component Matrix. Sebuah indikator dinyatakan berperan sebagai pembentuk faktor ditunjukkan oleh nilai loading factor tertinggi. Hasil penelitian menunjukkan bahwa indikator motivasi, sikap pimpinan, hubungan pimpinan dengan karyawan, hubungan karyawan dengan karyawan, ruangan kerja dan punishment mempunyai nilai loading factor tertinggi dalam membentuk faktor 1. Indikator gaji/upah, THR, bonus, job description, libur, dan reward mempunyai nilai loading factor tertinggi dalam membentuk faktor 2. Indikator jaminan keselamatan dan jaminan kesehatan mempunyai nilai loading factor tertinggi dalam membentuk faktor 3. Selengkapnya perhatikan tabel 4. 
Tabel 4.

Hasil Uji Rotated Component Matrix

\begin{tabular}{lccc}
\hline & \multicolumn{3}{c}{ Component (Variable) } \\
\cline { 2 - 4 } & 1 & 2 & 3 \\
\hline Gaji/Upah & 0,108 & $\mathbf{0 , 8 0 5}$ & 0,329 \\
THR & 0,186 & $\mathbf{0 , 8 5 8}$ & 0,069 \\
Bonus & 0,371 & $\mathbf{0 , 7 2 6}$ & 0,069 \\
Motivasi & $\mathbf{0 , 8 2 2}$ & 0,215 & 0,125 \\
Sikap pimpinan & $\mathbf{0 , 7 9 0}$ & 0,284 & 0,114 \\
Hubungan Pimpinan-Karyawan & $\mathbf{0 , 6 5 7}$ & 0,217 & 0,317 \\
Hubungan Karyawan-Karyawan & $\mathbf{0 , 7 6 5}$ & 0,130 & 0,305 \\
Job description & 0,384 & $\mathbf{0 , 5 5 0}$ & 0,441 \\
Libur & 0,416 & $\mathbf{0 , 5 5 8}$ & 0,163 \\
Ruang kerja & $\mathbf{0 , 5 9 1}$ & 0,521 & 0,312 \\
Reward & 0,570 & $\mathbf{0 , 6 0 0}$ & 0,178 \\
Punishment & $\mathbf{0 , 6 7 8}$ & 0,380 & 0,174 \\
Jaminan keselamatan & 0,203 & 0,346 & $\mathbf{0 , 8 3 6}$ \\
Jaminan kesehatan & 0,279 & 0,066 & $\mathbf{0 , 8 4 8}$ \\
\hline
\end{tabular}

Extraction Method: Principal Component Analysis.

Rotation Method: Varimax with Kaiser Normalization.

a. Rotation converged in 5 iterations.

Sumber: Hasil output SPSS

Sebagai langkah akhir dari penentuan faktor, maka dapat dilihat Component Transformation. Component Transformation Matrix berfungsi membuktikan besarnya nilai korelasi dari faktor yang terbentuk (Santoso, 2015: 87). Lebih jelasnya perhatikan tabel 5.

Tabel 5.

Hasil Uji Component Transformation Matrix

\begin{tabular}{cccc}
\hline Component (Variable) & 1 & 2 & 3 \\
\hline 1 & $\mathbf{0 , 6 7 7}$ & 0,617 & 0,402 \\
2 & 0,582 & $\mathbf{- 0 , 7 8 3}$ & 0,221 \\
3 & $-0,451$ & $-0,084$ & $\mathbf{0 , 8 8 9}$ \\
\hline
\end{tabular}

Extraction Method: Principal Component Analysis.

Rotation Method: Varimax with Kaiser Normalization.

Sumber: Hasil output SPSS

Berdasarkan tabel 5 dapat dilihat bahwa nilai korelasi masing-masing faktor yang terbentuk $>0,5(0,677,0,783$, dan 0,889$)$. Tanda “_“" (minus) pada faktor dua hanya menunjukkan arah korelasi saja, namun tetap dianggap dapat merangkum indikator. Berarti dapat disimpulkan ketiga faktor yang terbentuk sudah tepat dalam merangkum ke-14 indikator yang ada. Berdasarkan faktor baru yang terbentuk, maka dapat dinamai bahwa faktor 1 adalah faktor hubungan sosial, faktor 2 adalah faktor 
upah/gaji dan, faktor 3 adalah faktor jaminan bekerja dalam meningkatkan kepuasan kerja dan loyalitas PT Golden Kirrin Internasional.

\subsection{Loyalitas Karyawan PT Golden Kirrin Internasional}

Loyalitas karyawan PT Golden Kirrin Internasional, dapat dilihat dari penilaian karyawan untuk tidak berpindah ke perusahaan lain (no switch), diikuti dengan penilaian positif terhadap perusahaan, dan penilaian positif terhadap kinerja karyawan. Distribusi loyalitas karyawan dapat dilihat pada tabel 6.

Tabel 6.

Distribusi Loyalitas Karyawan PT Golden Kirrin Tahun 2017

\begin{tabular}{llcc}
\hline No & Indikator & Rata-Rata Skor & Kategori \\
\hline 1 & No Switch ke perusahaan lain & 4,26 & Sangat puas \\
2 & Peniliain positif terhadap perusahaan & 4,46 & Sangat puas \\
3 & $\begin{array}{l}\text { Penilaian positif terhadap kinerja } \\
\text { karyawan }\end{array}$ & 4,32 & Sangat puas \\
\hline \multicolumn{2}{c}{ Rata-rata } & 4,35 & Sangat puas \\
\hline
\end{tabular}

Sumber: Diolah dari data primer

Berdasarkan tabel 6 diatas dapat dilihat loyalitas karyawan untuk tidak berpindah keperusahaan lain (no switch), penilaian positif terhadap perusahaan, dan penilaian positif terhadap kinerja karyawan sangat baik. Dilihat dari nilai rata-rata keseluruhan pemberian skor sebesar 4,35 yang artinya karyawan yang berkerja di PT Golden Kirrin sangat puas terhadap kinerja perusahaan dan karyawan dan sangat loyal degan PT Golden Kirrin Internasional.

\section{Simpulan dan Saran}

\subsection{Simpulan}

Terbentuk tiga faktor yang mempengaruhi kepuasan kerja dan loyalitas karyawan PT Golden Kirrin Internasional yaitu: faktor sosial dengan indikatorindikator yaitu: motivasi, sikap pimpinan, hubungan pimpinan dengan karyawan, hubungan karyawan dengan karyawan, ruangan kerja, dan punishment. Faktor gaji/upah dengan indikator-indikatornya yaitu: gaji/upah, THR, bonus, job description, libur, dan reward. Faktor jaminan bekerja dengan indikator-indikatornya yaitu: jaminan keselamatan dan jaminan kesehatan. Ketiga faktor yang terbentuk menyimpulkan bahwa kepuasan dan loyalitas karyawan PT Golden Kirrin Internasional semata-mata tidak disebabkan besarnya gaji/upah dan jaminan bekerja yang diberikan perusahaan kepada karyawannya, namun kepuasan kerja dan loyalitas karyawan lebih dominan disebabkan hubungan sosial yang sangat kuat terjalin di PT Golden Kirrin Internasional. Karyawan PT Golden Kirrin Internasional juga sangat 
puas terhadap kinerja perusahaan dan karyawan serta sangat loyal terhadap perusahaan PT Golden Kirrin Internasional.

\subsection{Saran}

Saran yang dapat diberikan dari hasil penelitian ini kepada PT Golden Kirrin Internasional adalah agar pimpinan PT Golden Kirrin Internasional dapat mempertahankan tingkat kepuasan dan loyalitas karyawan khususnya pada faktor sosial dan gaji/upah. Faktor ini sangat berdampak signifikan pada pencapaianpencapaian yang telah ditetapkan perusahaan. Pada faktor jaminan bekerja, pimpinan perusahaan tetap harus memperhatikannya sebab faktor tersebut mendukung terciptanya kesejahteraan karyawan yang bekerja.

\section{Ucapan Terimakasih}

Terimakasih kepada seluruh pihak yang telah memberikan pengarahan, bimbingan serta dukungan dalam penyelesaian penelitian dan penulisan e-jurnal ini. Semoga penelitian ini dapat bermanfaat sebagaimana mestinya

\section{Daftar Pustaka}

Antara, M. 2006. Bahan Ajar Mata Kuliah Metode Penelitian Agribisnis. Program Studi Magister Agribisnis, Program Pasca Sarjana Universitas Udayana: Denpasar.

Handoko, T. Hani. 2000. Manjamen Edisi 2. BPFE: Yogyakarta.

Hariandja, M.T.E. 2002. Manajemen Sumberdaya Manusia. PT Gramedia Widiarsana Indonesia: Jakarta.

Istijanto, M.M. 2005. Riset Sumber Daya Manusia. PT Gramedia Pustaka Utama: Jakarta.

Maslow, A.H. 1943. "A Theory of Human Motivation.” Psychological Review, 50(4), 370-96.

Mathis, R. L. dan Jackson, H. 2001. Manajemen Sumberdaya Manusia. Salemba Empat: Jakarta.

Santoso, S. 2015. Menguasai Statistik Multivariat. PT Elex Media Kumputindo: Jakarta.

Sarwono dan Martadiredja. 2008. Riset Bisnis dengan SPSS. Andi Offset: Jakarta.

Sevilla. C.G. 2007. Research Methods. Rex Printing Company: Quezo City.

Simamora, H. 1995. Manajemen Sumber Daya Manusia. Bagian Penerbitan Sekolah Tinggi Ilmu Ekonomi YKP: Yogyakarta.

Sugiyono. 2008. Metode Penelitian Kuantitatif Kualitatif Dan R\&D. CV Alfabeta: Bandung. 